\title{
Diffusion of crustal deformation from disturbances arising at plate boundaries-a case of the detachment beneath the Izu Peninsula, central Honshu, Japan-
}

\author{
Kana Takahashi and Tetsuzo Seno \\ Earthquake Research Institute, University of Tokyo, Japan \\ (Received June 28, 2004; Revised December 28, 2004; Accepted April 4, 2005)
}

\begin{abstract}
We carry out numerical simulation of disturbance propagation within a plate floating over a viscous layer based on the 2-dimensional equations of Lehner et al. (1981). We apply the results to the anomalous crustal movements in central Honshu that followed the dike intrusion event between Miyakejima and Kozushima in the mid of 2000. We assume that the anomalous crustal movements represent diffusive transfer of a slip on the detachment beneath the Izu Peninsula, that occurred at the time of the dike intrusion event, over thin viscous layers such as the fault gouge of nearby great interplate earthquakes (Seno, 2005). From the arrival times of the disturbance in the Tokai district, the diffusion coefficient is determined to be $50-150 \mathrm{~m}^{2} / \mathrm{s}$, and the viscosity of the fault gouge to be $10^{13}$ $10^{15} \mathrm{~Pa}$ s. This value of viscosity is significantly smaller than that of the asthenosphere, and would probably be caused by the elevation of pore fluid pressure close to the lithostatic in the rupture zones of nearby great earthquakes. The serpentinized wedge mantle landward of the rupture zones may also constitute part of the thin viscous layers.
\end{abstract}

Key words: Stress diffusion, detachment, dike intrusion, Izu Peninsula, viscosity, Tokai.

\section{Introduction}

Migration of crustal deformation has been discovered in subduction zones by tilt- and strainmeters. Yamada (1973), for example, compared tilts at two adjacent stations in the S. Kanto district, Japan, and suggested a migration of the tilt from the east to the west with a velocity of $\sim 20$ $\mathrm{km} / \mathrm{yr}$. Tanaka et al. (1977) studied tiltmeter records in the Cordillera Mts., Peru, and suggested a migration of the tilt to the north with a velocity of $60-70 \mathrm{~km} / \mathrm{yr}$. Ishii et al. (1980), using a strainmeter array in northern Honshu, Japan, suggested a migration of the strain to the northwest with a velocity of $\sim 40 \mathrm{~km} / \mathrm{yr}$.

Earthquake foci in a seismic zone also sometimes appear to migrate systematically in one direction. For example, in the N. Anatolia fault, Turkey, a series of major earthquakes migrated at a velocity of 60-70 km/yr (Mogi, 1968; Toksoz et al., 1979). Another example was recognized in the NW Pacific subduction zones where seismicity migrated with a velocity of 150-270 km/yr (Mogi, 1968).

Stress diffusion is generally said to be a reason for such migration of crustal deformation and seismicity occurs. A rapid change of the displacement or stress at a plate boundary is transmitted in diffusion by the influence of a viscous layer below (Elsassar, 1967). Bott and Dean (1973), Anderson (1975), and Kasahara (1979) showed that the speed of migration of crustal deformation and seismicity is conformable to that expected from the viscosity of the astheno-

Copyright (c) The Society of Geomagnetism and Earth, Planetary and Space Sciences (SGEPSS); The Seismological Society of Japan; The Volcanological Society of Japan; The Geodetic Society of Japan; The Japanese Society for Planetary Sciences; TERRAPUB sphere. Ida (1974) treated thin fault gouge as a viscous layer instead of the asthenosphere, and obtained an expression of the migration speed of displacements. He estimated the viscosity of the fault gouge to be $10^{11}-10^{14} \mathrm{~Pa}$ s in the San Andreas fault from observed seismicity migration. Sato (1989) and Rydelek and Sacks (1990) let the viscous layer to be viscoelastic, and applied the results to crustal deformation and seismicity in N. Honshu, Japan. Lehner et al. (1981) and Heki et al. (1993) constructed a 2-dimensional model of the stress diffusion.

In this study, based on the 2-dimensional equations of Lehner et al. (1981), we will carry out numerical calculations of crustal deformation propagated from an assumed slip on a horizontal detachment beneath the Izu Peninsula, which Seno (2005) proposed to have occurred during the dike intrusion event between Miyakejima and Kozushima in the mid of 2000 (the Miyake-Kozu event hereinafter). To compare the results with observed data, we refer to the anomalous crustal movements in central Honshu that have occurred after the Miyake-Kozu event and estimate the viscosity of the viscous layers.

\section{2-Dimensional Equations}

The derivation of 2-dimensional equations describing the migration of deformation below follows Lehner et al. (1981), in which the average stress disturbance in the thickness direction is negligible in comparison with the in-plane components and the plane stress condition is applied. This should be appropriate for disturbances of dominant wavelengths that are comparable to or greater than a plate thickness (see Lehner et al., 1981). In the present study, because 


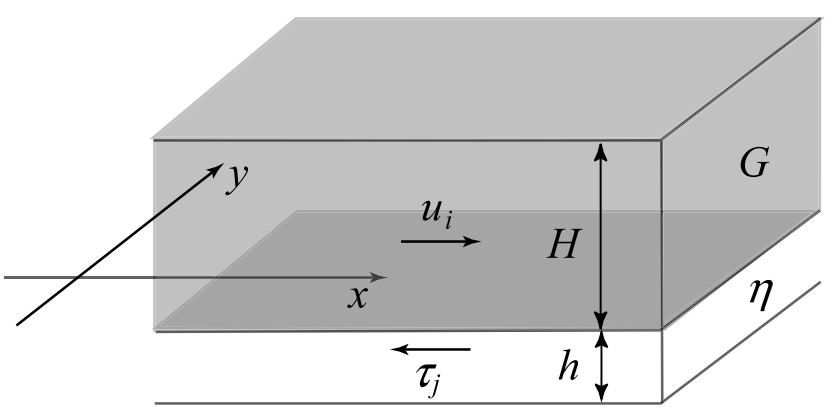

Fig. 1. Two-dimensional model of stress diffusion. In this model, an isotropic elastic plate with the thickness $H$ and the rigidity $G$ rides on a viscous layer with the thickness $h$ and the viscosity $\eta . u_{i}$ is the horizontal displacements averaged over the plate thickness and $\tau_{i}$ is the shear stress at the bottom of the plate.

disturbances occur on the horizontal detachment whose dimension is larger than the plate thickness, as will be shown later, this seems eligible. Let an elastic lithospheric plate of a uniform thickness $H$ ride on a viscous layer of a uniform thickness $h$, and $u_{i}$ and $\sigma_{i j}(i, j=x, y)$ be displacements and stresses in the horizontal plane of the plate, respectively, averaged over the plate thickness (Fig. 1). The equations of equilibrium are

$$
\frac{\partial \sigma_{i j}}{\partial x_{i}}=\frac{\tau_{j}}{H}
$$

where $\tau_{j}$ is the shear traction acting on the bottom of the plate in the negative $j$-direction. The stress-strain relations for an isotropic material under plane stress conditions are

$$
\sigma_{i j}=G\left[\frac{\partial u_{i}}{\partial x_{j}}+\frac{\partial u_{j}}{\partial x_{i}}+\frac{2 v}{1-v} \frac{\partial u_{\gamma}}{\partial x_{\gamma}} \delta_{i j}\right],
$$

where $G$ is the shear modulus and $v$ is the Poisson's ratio of the plate. Summation over $x$ and $y$ is implied by repeated Greek indices. The relation between stress $\tau_{i}$ and displacement $u_{i}$ at the top of the viscous layer is

$$
\tau_{i}=\frac{\eta}{h} \dot{u}_{i}
$$

where $\eta$ is the viscosity of the viscous layer. Combining (1), (2), and (3) gives,

$$
\alpha\left\{\frac{\partial^{2} u_{i}}{\partial x_{\gamma} \partial x_{\gamma}}+\frac{1+v}{1-v} \frac{\partial^{2} u_{\gamma}}{\partial x_{i} \partial x_{\gamma}}\right\}=\frac{\partial u_{i}}{\partial t},
$$

where

$$
\alpha=\frac{h H G}{\eta} .
$$

The following non-dimensionalization is performed before calculation as

$$
\begin{aligned}
& \frac{\partial^{2} u_{x}}{\partial \zeta^{2}}+\frac{\partial^{2} u_{x}}{\partial \xi^{2}}+\frac{1+v}{1-v}\left(\frac{\partial^{2} u_{x}}{\partial \zeta^{2}}+\frac{\partial^{2} u_{y}}{\partial \zeta \partial \xi}\right)=\frac{\partial u_{x}}{\partial \tau}, \\
& \frac{\partial^{2} u_{y}}{\partial \zeta^{2}}+\frac{\partial^{2} u_{y}}{\partial \xi^{2}}+\frac{1+v}{1-v}\left(\frac{\partial^{2} u_{x}}{\partial \xi \partial \zeta}+\frac{\partial^{2} u_{y}}{\partial \xi^{2}}\right)=\frac{\partial u_{y}}{\partial \tau},
\end{aligned}
$$

where

$$
\tau=\frac{\alpha t}{L^{2}}, \quad \zeta=\frac{x}{L}, \quad \xi=\frac{y}{L}
$$

and $L$ is an arbitrary length comparable to $H$.

\section{The Anomalous Crustal Deformation in Cen- tral Honshu}

South of central Honshu, there is a convergent plate boundary along the Sagami-Suruga troughs where the Philippine Sea plate is subducting (Fig. 2). Between these troughs, the Izu Peninsula, which is the northern edge of the Izu-Bonin volcanic ridge, has been colliding with central Honshu. The Tokai and Kanto regions, located landward of the Suruga and Sagami troughs, respectively, have experienced great interplate earthquakes historically (Ishibashi, 1981; Kasahara et al., 1973), and the Tokai region is believed to have a great earthquake in the near future (Ishibashi, 1981; Seno, 2004).

A large seismo-magmatic activity started near Miyakejima in the Izu islands south of the Izu Peninsula, on June 26, 2000, and expanded to the northwest close to Kozushima (Sakai et al., 2001). A large volume of dike $\left(\sim 1 \mathrm{~km}^{3}\right)$ intruded between Miyakejima and Kozushima $\sim 20 \mathrm{~km}$ in length (i.e., the Miyake-Kozu event, Yamaoka, 2000; Nishimura et al., 2001; Ito and Yoshioka, 2002). Interestingly, ramp-shaped horizontal displacements having amplitudes of an order of $\sim 1 \mathrm{~cm}$ were distributed far inland of central Honshu with a duration of $\sim 85$ days (Geographical Survey Institute, 2003; See also Yamaoka et al., 2005 and Seno, 2005). Kobayashi et al. (2003) attributed this wide-spread crustal deformation in central Honshu to a kind of viscoelastic response to the Miyake-Kozu event. After the activity faded out, the so-called abnormal crustal deformation in the Tokai-central Honshu-Kanto region started (Geographical Survey Institute, 2003; Ozawa et al., 2002; Fig. 3). This abnormal deformation has been attributed to the slow slip at the deep thrust beneath Lake Hamana (e.g., Ozawa et al., 2002), although the distribution of the deformation spread over central Honshu (Fig. 3).

Seno (2005) suggested that a sudden large slip occurred on the horizontal detachment beneath the Izu Peninsula during the dike intrusion event, to explain the wide spread displacements in central Honshu. He assigned a slip of $20 \mathrm{~cm}$, directing to $\mathrm{S} 60^{\circ} \mathrm{E}$, on the detachment at a depth of $20 \mathrm{~km}$; the fault geometry is shown in Fig. 4. He also suggested that the abnormal crustal movements in central Honshu after the dike intrusion event have been caused by diffusion of the slip on the detachment over low viscosity layers surrounding the detachment, such as fault gouge of nearby great interplate earthquakes with elevated pore fluid pressures, and serpentinized forearc mantle wedges further landward. We test this hypothesis by calculating deformation migrating from the initial slip on the detachment.

\section{Numerical Simulation}

The detachment beneath the Izu Peninsula proposed by Seno (2005) constitutes a boundary between the Philippine Sea plate and the overriding plate. To the west and the east, the overriding plate is floating over the fault gouge of the Tokai and Kanto earthquakes and, further landward, over the asthenospheric mantle wedges (Fig. 2). This geometry is simplified so that a plate with a uniform thickness of $30 \mathrm{~km}$ is floating on a horizontal viscous layer as shown in Fig. 1. Therefore we ignore the 3-dimensional complexities of the plate and plate interface structures such as the 


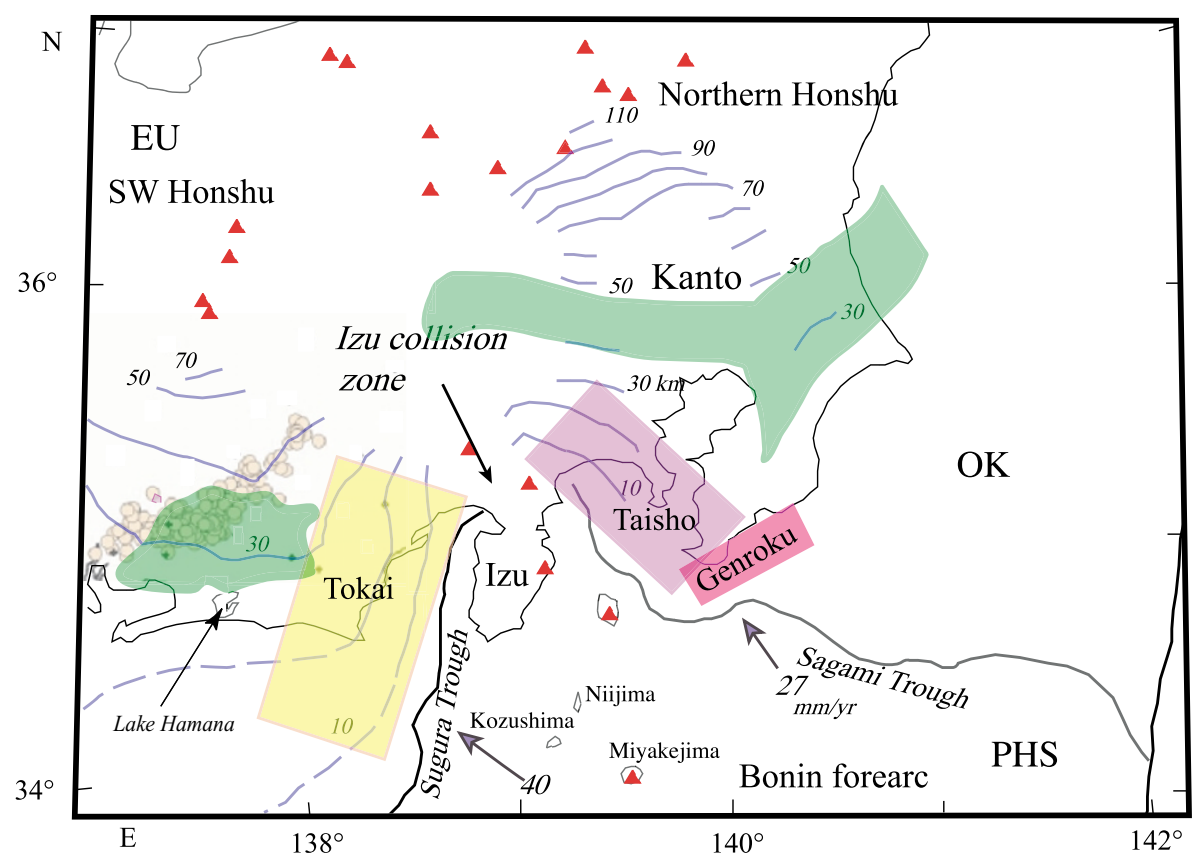

Fig. 2. Tectonic elements in central Honshu-Izu islands region (modified from Seno, 2005). The Philippine Sea plate is subducting along the Sagami Trough and the Nankai Trough with the velocities of $27 \mathrm{~mm} / \mathrm{yr}$ and $40 \mathrm{~mm} / \mathrm{yr}$, respectively (Seno et al., 1993, 1996). The Izu Peninsula is colliding with central Honshu. The contours show the upper surface of the intraslab seismicity (Noguchi and Sekiguchi, 2001). The fault planes are those of the Taisho and Genroku Kanto earthquakes (Kasahara et al., 1973), and the Tokai earthquake (Ishibashi, 1981). Low-frequency tremors (brown dots) are from Obara (2002). The possibly serpentinized wedge mantle revealed by the seismic tomography (Kamiya and Kobayashi, 2000, 2005) is shaded by green. The red triangles indicate active volcanoes.

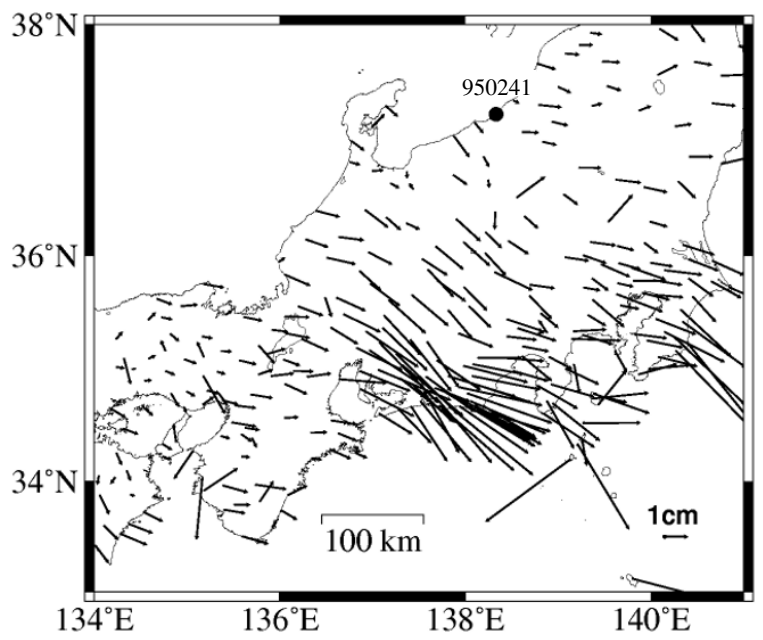

Fig. 3. Non-stationary horizontal displacements in central Honshu during March 27, 2001 and May 29, 2004, in which the stationary displacements extrapolated from the trend for the period before 2000 are extracted from the observed ones (Geographical Survey Institute, http://cais.gsi.go.jp/tokai/sabun/index.html). The Ohgata station (950241) is fixed. The displacements are seen in a wide area of central Honshu, which almost coincides with the area deformed at the time of the Miyake-Kozu dike intrusion event.

$20 \mathrm{~km}$ depth of the detachment beneath the Izu Peninsula. Although we admit that this might be oversimplification for such a place where transition from collision to subduction occurs, the purpose of this study is to show a possibility of diffusive transfer of crustal deformation for the anomalous displacements in central Honshu shown in Fig. 3, and not to mimic exactly the observed displacement field. The vis- cous layer thickness is not known, but we use $20 \mathrm{~m}$ that is the thickness of the decollement at the deformation front of the Nankai Trough (Ienaga, 2003).

To obtain the crustal deformation migrated from the slip on the detachment, we solve Eqs. (6)-(7) using the finite difference method under appropriate initial and boundary conditions. The detachment has a size of $85 \mathrm{~km} \times 35 \mathrm{~km}$ with a strike of $\mathrm{S} 10^{\circ} \mathrm{E}$ (Fig. 4). The initial disturbance given in the detachment has a step or ramp function with a total displacement of $20 \mathrm{~cm}$ in the direction of $\mathrm{S} 60^{\circ} \mathrm{E}$. A grid spacing of $0.5 \mathrm{~km}$ and a time step of 0.0002 in a non-dimensional unit defined by Eq. (8) are used in the computation. The calculation range has a size of $800 \mathrm{~km} \times$ $800 \mathrm{~km}$ and their boundaries are fixed. This fixed boundary condition is adequate because the time for the diffusion to reach the boundaries takes $\sim 50$ years for the diffusion coefficient considered in this study and, on the other hand, the time period concerned is less than 10 years. We take $L$ to be $10 \mathrm{~km}$. Although the calculation range contains the region south of the Izu Peninsula, this is only for the sake of numerical calculations, and the results in this region should be discarded.

In this calculation, we reduce the diffusion coefficient inland of central Honshu to $1 / 10$ of that of the coastal region as shown in Fig. 4 because amplitudes of the observed horizontal movements in inland areas are small. This would be caused by the existence of normal asthenosphere further landward of the serpentinized mantle wedges (Fig. 2). We show later that this reduction of the diffusion coefficient is consistent with the viscosity of the asthenosphere beneath this region. 


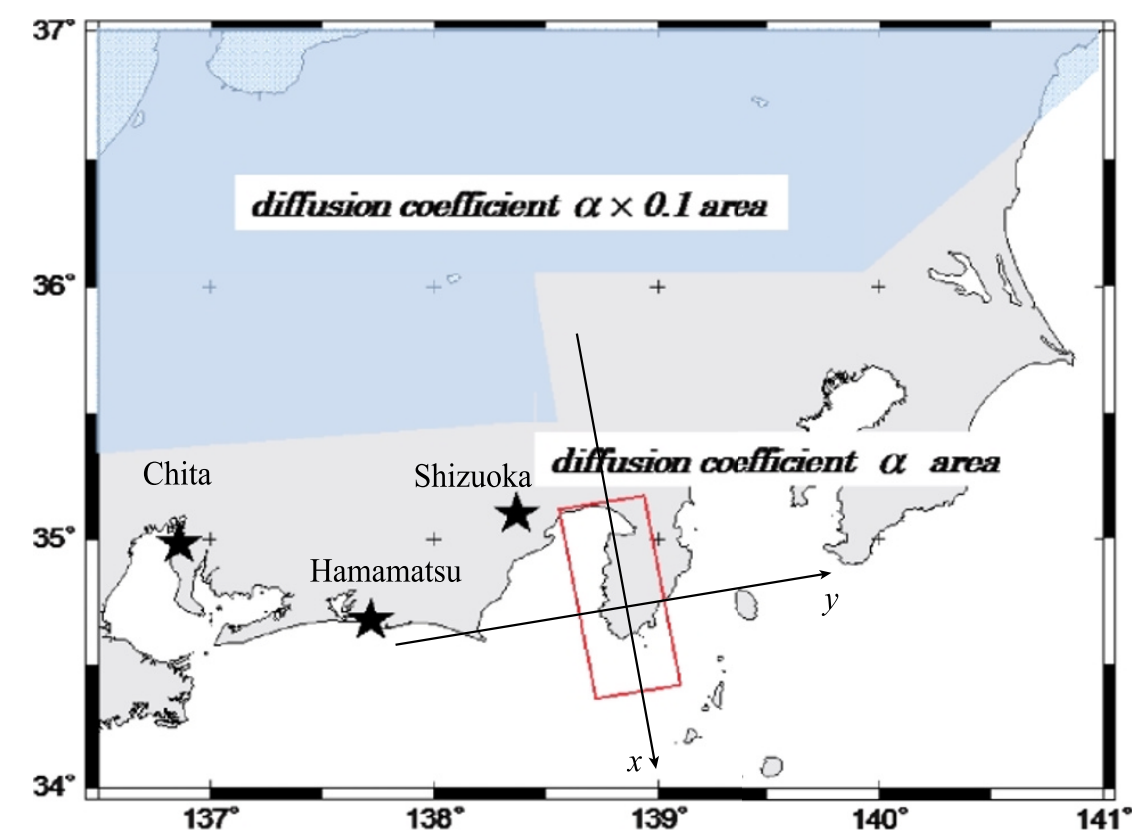

Fig. 4. Frame of the computation of horizontal displacements. The source of disturbance is put on the rectangle following Seno (2005). The three permanent GPS stations, i.e. Shizuoka2, Hamamatsu and Chita, used for comparison with the observed data, are indicated by the stars. The diffusion coefficient in the shaded area is reduced to $1 / 10$ of that of the coastal region.

By the analysis of GPS data, Ozawa et al. (2002) suggested that the anomalous crustal deformation started around October 2000 near Lake Hamana and became evident by the beginning of 2001 in the Tokai district. Therefore, we regard the disturbance due to the slip on the detachment arrived at the Tokai district between 3 and 9 months after June 26, that is the start time of the dike intrusion event. To fit this arrival time, we use two permanent GPS stations, i.e., Hamamatsu and Chita (Fig. 4). We regard the time when the amplitude of $0.01 \mathrm{~cm}$ or $0.1 \mathrm{~cm}$ of the total horizontal displacement arrives at these stations as the arrival time. In this case, a step function shape disturbance is given at the source. Equating the arrival time to be 3 and 9 months, we obtain $\alpha=48-144 \mathrm{~m}^{2} / \mathrm{s}$ and $\alpha=28-80$ $\mathrm{m}^{2} / \mathrm{s}$, respectively, at Hamamatsu. Similarly, at Chita, we obtain $\alpha=120-360 \mathrm{~m}^{2} / \mathrm{s}$ and $\alpha=70-208 \mathrm{~m}^{2} / \mathrm{s}$, respectively. From these, we determine $\alpha$ to be $50-150 \mathrm{~m}^{2} / \mathrm{s}$, and viscosity $\eta$ of the viscous layers to be $10^{14}-10^{15} \mathrm{~Pa} \mathrm{~s}$, if we take $G=10^{11} \mathrm{~Pa}$. If we take $G=10^{10} \mathrm{~Pa}, \eta$ becomes $10^{13}-10^{14} \mathrm{~Pa} \mathrm{~s}$.

Figure 5 shows the comparison between the calculated and observed time series of the horizontal displacements for the case of $\alpha=50 \mathrm{~m}^{2} / \mathrm{s}$ at the three GPS stations (Shizuoka2, Hamamatsu and Chita). In this case, a ramp function shape disturbance with a rise time of 85 days is given at the source. At Hamamatsu, the amplitudes of the time series of the calculated displacements are similar to those observed by GPS. The amplitudes of the calculated displacements at Shizuoka2 and Chita are apparently larger and smaller, respectively, than those observed. Figure 6 shows the spatial distribution of the calculated horizontal displacements at 3.5 years after June 26, 2000; the initial displacements until March 26, 2001 are eliminated to compare with those in Fig. 3. The pattern fits grossly the observed one in central Honshu (Fig. 3), although the ampli- tudes show some discrepancy. This point will be discussed later.

\section{Discussion}

\subsection{The value of viscosity}

The viscosity of the viscous layers obtained in this study, i.e., $10^{13}-10^{15} \mathrm{~Pa} \mathrm{~s}$, is significantly smaller than that of the asthenosphere, i.e., $10^{19}-10^{20} \mathrm{~Pa} \mathrm{~s}$ (Thatcher et al., 1980; Nakada and Lambeck, 1987; Rydelek and Sacks, 1990; Suito and Hirahara, 1999). Ida (1974) estimated the viscosity of the fault gouge in the San Andreas as $10^{11}$ $10^{14} \mathrm{~Pa} \mathrm{~s}$, assuming the thickness of the gouge to be $1 \mathrm{~m}$. If the gouge thickness of $20 \mathrm{~m}$ is used, his viscosity value becomes similar to that of the present study. If the viscosity of the viscous layers are not so low, the disturbance could hardly spread in diffusion. For example, if the value of viscosity is $10^{19} \mathrm{~Pa} \mathrm{~s}$, diffusion over a distance of $10 \mathrm{~km}$ will take $10^{3}-10^{4}$ years and the anomalous crustal deformation will not be seen in central Honshu.

The above low value indicates that the material of the low viscosity layers is not typical crustal or mantle rock. We suggest two possibilities: one is the effect of elevated pore fluid pressure in the fault gouge of great interplate earthquakes and the other is the effect of weak material such as serpentine in the forearc mantle wedge. The fault zones of the Tokai and Kanto earthquakes are located at the crustal depth and part of them (asperities) are locked hard to cause great earthquakes. A number of papers have discussed the possibility of elevation of the pore fluid pressure in fault zones in the transform or subduction plate boundaries (see Hickman et al. (1995) and Seno (2003) for the literature). Since the last event in 1854 in the Tokai district, 150 years have passed, and since the Taisho Kanto earthquake in 1923, 80 years have passed. It is, therefore, likely that the pore fluid pressure has been elevated in the fault 
(a)
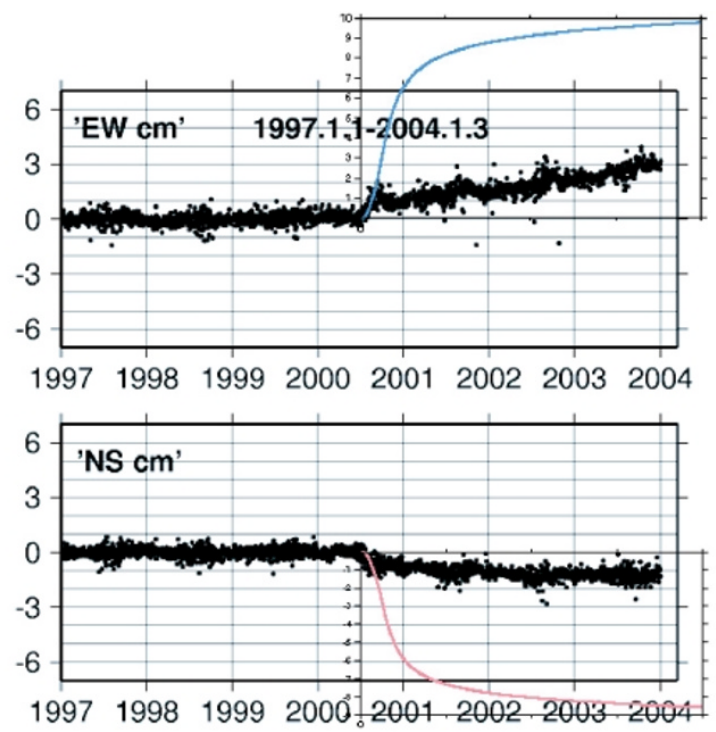

(b)

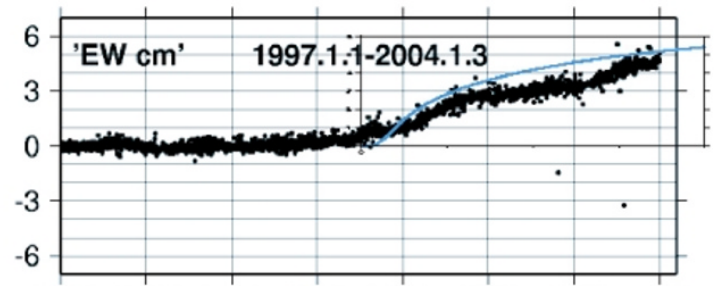

19971998199920002001200220032004

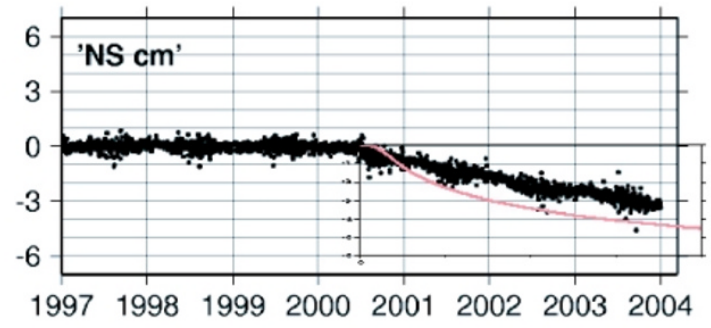

(c)

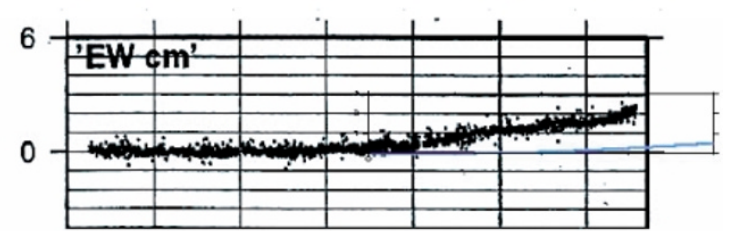

$199719981999200020012002 \quad 2003$

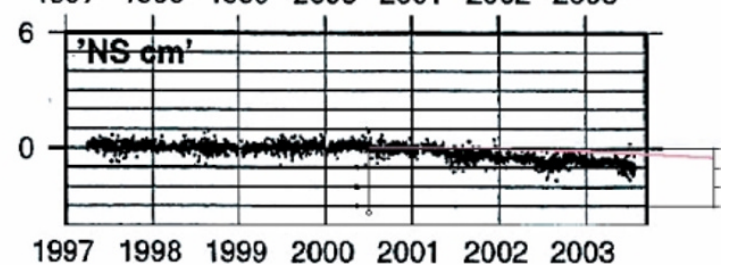

Fig. 5. Comparison between the calculated and observed horizontal displacements at (a) Shizuoka2, (b) Hamamatsu, and (c) Chita. A ramp-shape displacement of $20 \mathrm{~cm}$ with a rise time of 85 days is given at the source as an initial disturbance, and $\alpha=50 \mathrm{~m}^{2} / \mathrm{s}$ is used. The calculated displacements are too large and too small for Shizuoka and Chita, respectively (see discussion in the text).

gouge of these earthquakes, and the gouge would constitute low viscosity layers.

We note here that the observed abnormal crustal deformation is the deviation from the secular deformation, and the drag of the upper plate by the subducting Philippine Sea plate through the locked interplate must have been continuing even after the dike intrusion event. If whole part of the rupture zones of nearby great earthquakes constitutes a low viscosity zone, it would be difficult to lock the plate interface prior to a coming earthquake. However, Seno (2003) proposed that only barrier portion of a rupture zone of a great earthquake will have elevated pore fluid pressures (socalled barrier invasion), and remaining asperity part, on the other hand, can lock the plate interface. Because barrier portion occupies more than $60 \%$ of the whole rupture zone (Seno, 2003), propagation of the diffused crustal deformation seems possible through the invaded barriers. However, the viscosity of the fault gouge with elevated pore fluid pressure has not been obtained experimentally and further studies are necessary to confirm the effect of invaded barriers.

In the areas landward of the rupture zones, the subducting Philippine Sea plate contacts the mantle wedges of the upper plate. Kamiya and Kobayashi $(2000,2005)$ inferred that the wedges are serpentinized based on the high $V_{p} / V_{s}$ (Fig. 2). The serpentine is likely to be very weak if dehydration occurs (Raleigh and Paterson, 1965), and the serpenitinized mantle wedges might produce a similar effect to the high pore pressure in the gouge, acting as low viscous layers.

\subsection{Anomalous crustal movements in central Honshu}

The observed horizontal displacements shown in Fig. 3 are different in details from the calculated ones shown in Fig. 6. Although the purpose of our study is not to mimic the deformation pattern exactly by the numerical calculations, but to show the possibility of diffusive propagation of the slip, as stated before, it is noteworthy to mention about possible causes for the discrepancy.

The southeastward displacements in the SE Boso Peninsula, Kanto, are a few times larger than shown in Fig. 6. The large vectors directing to the southeast are likely due to the slow slip event that occurred beneath the southeastern part of the Boso Peninsula and the offshore area from October to December in 2002 (Ozawa et al., 2003). The rest of the horizontal displacements in this peninsula are more or less similar to those calculated.

The anomalous crustal deformation (Fig. 3) has been particularly large near Lake Hamana in the Tokai district. This is the reason why Ozawa et al. (2002) regarded the slow slip at the plate boundary in this area as the cause of the crustal deformation. The deformation might have been enlarged by the existence of the serpentinized mantle, because the area almost coincides with the high $V_{p} / V_{s}$ region of Kamiya and Kobayashi (2005). Recently, Kodaira et al. (2004) suggested that a high $V_{p} / V_{s}$ zone exists in the crust of the subducted ridges with elevated pore pressures in the slow slip region of Ozawa et al. (2002). We do not take this view because similar high $V_{p} / V_{s}$ zones are seen in some places of the SW Japan forearc wedge mantle (Honda and Nakanishi, 2003; S. Kamiya, personal comm., 2004). Even if this is the case, however, a similar low viscosity effect would be expected.

The discrepancy in amplitudes of displacements between the observed and calculated ones at Shizuoka 2 and Chita may also be due to heterogeneous viscosity distribution in 


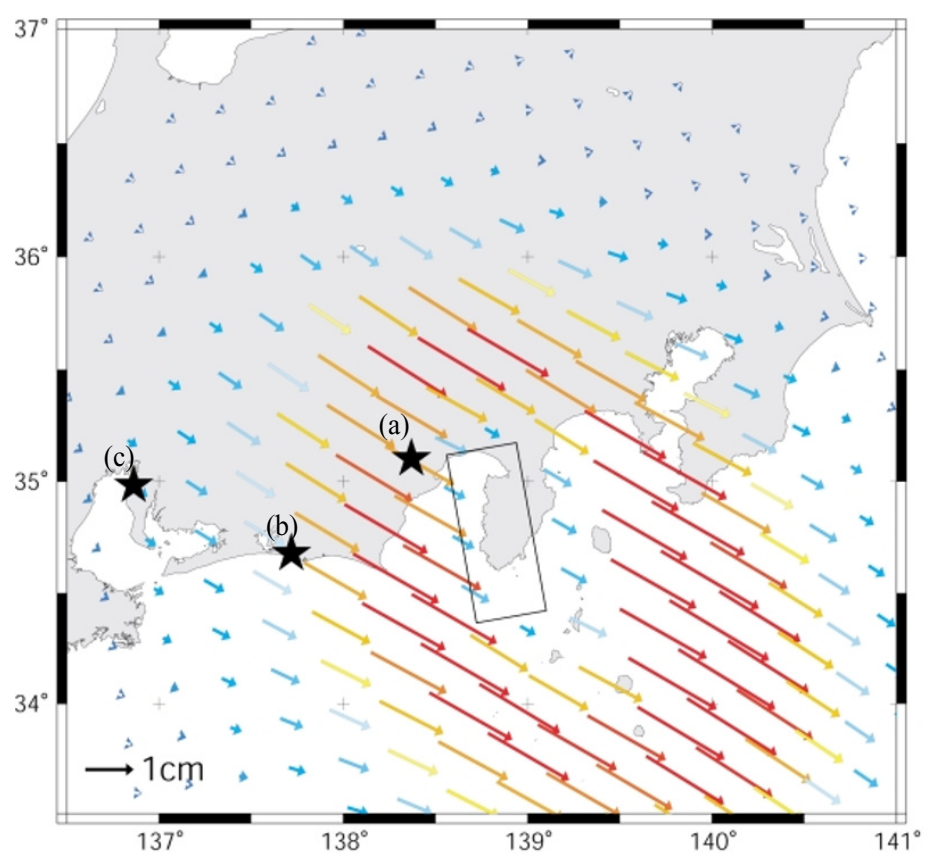

Fig. 6. Spatial distribution of displacement vectors at $t=3.5 \mathrm{yrs}$ after the start of the dike intrusion event. The initial displacements until March 26, 2001 are eliminated to compare with those in Fig. 3. A ramp-shape displacement of $20 \mathrm{~cm}$ with a rise time of 85 days is given at the source as an initial disturbance, and $\alpha=50 \mathrm{~m}^{2} / \mathrm{s}$ is used. The vectors in the south of the detachment are fake ones. Locations of Shizuoka2, Hamamatsu, and Chita are indicated by stars with labels (a), (b), (c), respectively.

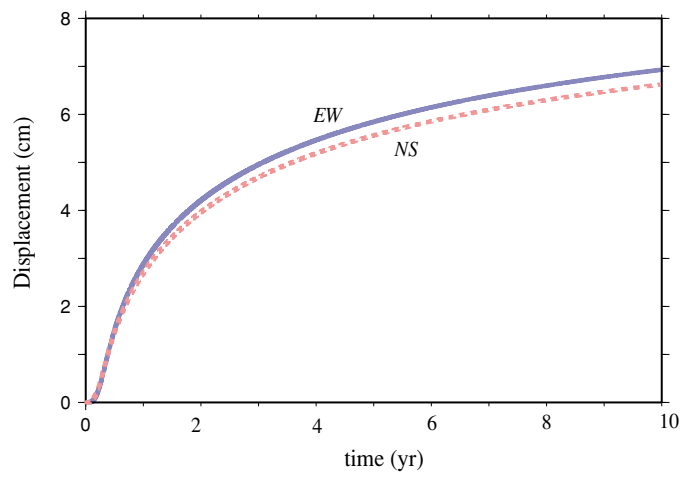

Fig. 7. Prediction of the time series of displacements at Hamamatsu for 10 years after the start of the dike intrusion event. A ramp-shape displacement of $20 \mathrm{~cm}$ with a rise time of 85 days is given at the source as an initial disturbance, and $\alpha=50 \mathrm{~m}^{2} / \mathrm{s}$ is used.

the viscous layers. Shizuoka2 is located at the edge of the rupture zone of the Tokai earthquake (Ishibashi, 1981; Matsumura, 1997). The propagation of the disturbance from the Izu Peninsula travels through the plate boundary lacking the elevation of the pore pressure. This would reduce the amplitude of the displacements. On the contrary, the path to Chita is over the high $V_{p} / V_{s}$ region and might enlarge the amplitudes.

In this study, we reduce the diffusion coefficient inland of central Honshu to $1 / 10$ of that of the coastal region because the observed displacements in the inland region are small. This is explained by the existence of the asthenosphere beneath the plate in the inland region. For the parameter values suitable for this region, i.e., $\eta=10^{20} \mathrm{~Pa}, H=30$ $\mathrm{km}$, and $h=200 \mathrm{~km}$, the diffusion coefficient becomes smaller by a factor $1 / 10$. Although much smaller astheno- spheric viscosities have been estimated in some places of northern-central Honshu (Ueda et al., 2003; Yamasaki and Seno, 2005), thickness of such low viscosity layers might be thin, which counteracts the low viscosities (see Eq. (5)). No more precise discussion seems useful in the simplified 2-dimensional geometry assumed in this study. It is also noted that some of the displacements in central Honshu might have been caused by the diffusion of the in-situ elastic deformation that occurred at the time of the dike intrusion event as discussed by Seno (2005).

\subsection{Future trend}

Based on the assumption in this study, we can predict that the so-called abnormal crustal deformation will fade out in the future. Figure 7 shows the horizontal displacements calculated at Hamamatsu during 10 years after the start of the dike intrusion event using $\alpha=50 \mathrm{~m}^{2} / \mathrm{s}$. It predicts that the displacement rate will become gentle after about 6 years. However, the observed data show that the displacement rate has increased recently (Fig. 5). The southeastward displacements of the GPS stations in the Izu Peninsula as seen in Fig. 3, for example, indicate that the slip on the Izu detachment may still continue after the end of the dike intrusion event. Therefore the observed time series might contain not only the components propagated from the slip on the detachment during the dike intrusion event, but also propagated from the slip occurring after it.

\section{Conclusions}

We carry out numerical simulations of propagation of deformation within a plate floating over a low viscosity layer, based on the 2-dimensional equations of Lehner et al. (1981). Applying the simulation results to the anomalous crustal movements observed by GPS in central Honshu, 
based on the assumption that a southeastward slip on the detachment beneath the Izu Peninsula during the MiyakeKozu dike intrusion event has propagated into central Honshu as the abnormal crustal movements, we estimate the value of the viscosity of the viscous layers as $10^{13}-10^{15}$ $\mathrm{Pa}$ s. This viscosity is significantly smaller than that of the asthenosphere. This might be caused by the elevated pore fluid pressure in the rupture zones of the coming great Tokai and Kanto earthquakes, and, further landward, by the serpentinized mantle wedges.

Acknowledgments. We thank Takuya Nishimura and Manabu Hashimoto for their critical review of the manuscript, and Takeshi Sagiya for useful comments. We also thank Teruyuki Kato, Takashi Miyatake, Yoshio Fukao, Satoru Honda and Takeo Ito for their useful advices during this study.

\section{References}

Anderson, D. L., Accelerated plate tectonics, Science, 187, 1077-1079, 1975.

Bott, M. H. P. and D. S. Dean, Stress diffusion from plate boundaries, Nature, 243, 339-341, 1973.

Elsasser, W. M., Convection and stress propagation in the upper mantle, in The Application of Modern Physics to the Earth and Planetary Interiors, edited by S. K. Runcorn, John Wiley, New York, 223-246, 1967.

Geographical Survey Institute, Crustal movements in the Tokai district, Rep. Corrd. Comm. Earthquake Predict., 69, 303-393, 2003.

Hickman, S., R. Sibson, and R. Bruhn, Introduction to special section: mechanical involvement of fluids in faulting, J. Geophys. Res., 100, 12831-12840, 1995 .

Heki, K., G. R. Foulger, B. R. Julian, and C.-H. Jahn, Plate dynamics near divergent boundaries: Geophysical implications of post-tectonic crustal deformation in NE Iceland, J. Geophys. Res., 98, 14279-14297, 1993.

Honda, S. and I. Nakanishi, Seismic tomography of the uppermost mantle beneath southwestern Japan: seismological constraints on modelling subduction and magmatism for the Philippine Sea slab, Earth Planets Space, 55, 443-462, 2003.

Ida, Y., Slow-moving deformation pulses along tectonic faults, Phys. Earth Planet. Inter., 9, 328-337, 1974.

Ienaga, M., The early stages of formation and evolution of the Nankai accretionary prism inferred from quantitative analysis of logging-whiledrilling and the core data, ODP Leg 196, Ph. D. thesis, Univ. of Tokyo, 2003.

Ishibashi, K., Specification of a soon-to-occur seismic faulting in the Tokai district, central Japan, based upon seismotectonics, Earthquake Prediction-An International Review, Maurice Ewing Series, 4, 297-332, 1981.

Ishii, H. et al., Characteristics of Strain Migration in the Northeastern Japan Arc (II), J. Geod. Soc. Jpn., 26, 17-25, 1980.

Ito, T. and S. Yoshioka, A dike intrusion model in and around Miyakejima, Niijima and Kozushima in 2000, Tectonophysics, 359, 171-187, 2002.

Kamiya, S. and Y. Kobayashi, Seismological evidence for the existence of serpentinized wedge mantle, Geophys. Res. Lett., 27, 819-822, 2000

Kamiya, S. and Y. Kobayashi, Seismological evidence for the existence of serpentinized wedge mantle in the Tokai district, 2005 (to be submitted).

Kasahara, K., Migration of crustal deformation, Tectonophysics, 52, 329_ $341,1979$.

Kasahara, K., J. Yamada, and M. Ando, Crustal movements in the southern Kanto district, and a related working hypothesis, Publications for the 50th anniversary of the Great Kanto earthquake, 1923, Earthq. Res. Inst., Univ. Tokyo, 103-116, 1973 (in Japanese).

Kobayashi, A., T. Yamamoto, H. Takayama, and A. Yoshida, Crustal deformation in the Chubu-Kanto region at and after the 2000 seismic and volcanic activity around the Northern Izu Islands, J. Geod. Soc. Jpn., 49, 121-133, 2003 (in Japanese)

Kodaira, S., T. Iidaka, A. Kato, J.-O. Park, T. Iwasaki, and Y. Kaneda, High pore fluid pressure may cause silent slip in the Nankai trough, Science, 304, 1295-1298, 2004.

Lehner, F. K., V. C. Li, and J. R. Rice, Stress diffusion along rupturing plate boundaries, J. Geophys. Res., 86, 6155-6169, 1981.

Matsumura, S., Focal zone of a future Tokai earthquake inferred from the seismicity pattern around the plate interface, Tectonophysics, 273, 271-
$291,1997$.

Mogi, K., Migration of seismic activity, Bull. Earthq. Res. Inst., 46, 53-74, 1968.

Nakada, M. and K. Lambeck, Glacial rebound and relative sea-level variations: a new appraisal, Geophys. J. R. Astron. Soc., 90, 171-224, 1987.

Nishimura, T., S. Ozawa, M. Murakami, T. Sagiya, T. Tada, M. Kaidzu, and M. Ukawa, Crustal deformation caused by magma migration in the northern Izu Islands, Japan, Geophys. Res. Lett., 19, 3745-3748, 2001.

Noguchi, S. and S. Sekiguchi, Subduction and deformation of the Philippine Sea and Pacific plates beneath the Kanto region, Earth Monthly, 23, 733-741, 2001 (in Japanese).

Obara, K., Nonvolcanic deep tremor associated with subduction in southwest Japan, Science, 296, 1679-1681, 2002.

Ozawa S., M. Murakami, M. Kaidzu, T. Tada, T. Sagiya, Y. Hatanaka, H. Yarai, and T. Nishimura, Detection and monitoring of ongoing aseismic slip in the Tokai region, central Japan, Science, 298, 1009-1021, 2002.

Ozawa, S., S. Miyazaki, Y. Hatanaka, T. Imakiire, M. Kaidzu, and M. Murakami, Characteristic silent earthquakes in the eastern part of the Boso peninsula, Central Japan, Geophys. Res. Lett., 30, doi:10.1029/2002GL016665, 2003.

Raleigh, C. B. and M. S. Paterson, Experimental deformation of serpentinite and its tectonic implications, J. Geophys. Res., 70, 3965-3985, 1965.

Rydelek, P. A. and I. S. Sacks, Asthenospheric viscosity and stress diffusion: a mechanism to explain correlated earthquakes and surface deformations in NE Japan, Geophys. J. Inter., 100, 39-58, 1990.

Sakai, S., T. Yamada, S. Ide, M. Mochizuki, H. Shiobara, T. Urabe, N. Hirata, M. Shinohara, T. Kanazawa, A. Nishizawa, G. Fujie, and H. Mikada, Magma migration from the point of view of seismic activity in the volcanism of Miyake-jima island in 2000, J. Geogr., 110, 145155, 2001 (in Japanese).

Sato, K., Numerical experiments on strain migration, J. Geod. Soc. Jpn., 35, 27-36, 1989 (in Japanese).

Seno, T., Fractal asperities, invasion of barriers, and interplate earthquakes, Earth Planets Space, 55, 649-665, 2003.

Seno, T., Intermediate-term precursors of great subduction zone earthquakes: An application for predicting the Tokai earthquake, Earth Planets Space, 56, 621-633, 2004.

Seno, T., Izu detachment hypothesis: A proposal of a unified cause for the Miyake-Kozu event and the Tokai slow event, Earth Planets Space, 57, this issue, 925-934, 2005.

Seno. T., S. Stein, and A. E. Gripp, A model for the motion of the Philippine Sea plate consistent with NUVEL-1 and geological data, J. Geophys. Res., 98, 17941-17948, 1993.

Seno, T., T. Sakurai, and S. Stein, Can the Okhotsk plate be discriminated from the North American plate?, J. Geophys. Res., 101, 11305-11315, 1996.

Suito, H. and K. Hirahara, Simulation of postseismic deformations caused by the 1896 Riku-u earthquake, northeast Japan: Re-evaluation of the viscosity in the upper mantle, Geophys. Res. Lett., 26, 2561-2564, 1999.

Tanaka, Y., S. Otsuka, and L. Lazo, Migrating crustal deformations in Peru, Abstr. Seism. Soc. Jpn., no. 2, 1977 (in Japanese).

Thatcher, W., J. B. Rundle, T. Matsuda, and T. Kato, Lithospheric loading by the 1896 Riku-u earthquake, northern Japan: Implications for plate flexure and asthenospheric rheology, J. Geophys. Res., 85, 6429-6435, 1980.

Toksoz, M. N., A. F. Shakal, and A. J. Micael, Space-time migration of earthquakes along the North Anatolian fault zone and seismic gaps, PAGEOPH, 117, 1258-1270, 1979.

Ueda, H., M. Ohtake, and H. Sato, Postseismic crustal deformation following the 1993 Hokkaido Nansei-oki earthquake, northern Japan: Evidence for a low-viscosity zone in the uppermost mantle, J. Geophys. Res., 108(B3), doi:10.1029/2002JB002067, 2003.

Yamada, J., A water-tube tiltmeter and its application to crustal movement studies, Spec. Bull. Earthq. Res. Inst., 10, 1-147, 1973 (in Japanese).

Yamaoka, K., What are occurring beneath the Miyake and Kozu islands?, Kagaku, 70, 926-935, 2000 (in Japanese).

Yamaoka, K., T. Kudo, M. Kawamura, F. Kimata, and N. Fujii, Longlastisng dike intrusion in the 2000 eruption of Miyakejima volcanoWhere did the magma come from?, Bull. Volcanol., 67, 231-242, 2005. Yamasaki, T. and T. Seno, High strain rate zone in Central Honshu resulting from the viscosity heterogeneities in the crust and mantle, Earth Planet. Sci. Lett., 232, 13-27, 2005.

K. Takahashi and T. Seno (e-mail: seno@eri.u-tokyo.ac.jp) 